\title{
Clinical features and prognostic factors in 190 cancer patients with brain metastases
}

\author{
Min-Hang Zhou", Yuan Wü, Jun-Zhong Sun \\ Department of Geriatric Oncology, Fourth Medical Center of the People's Liberation Army General Hospital, Beijing 100048, China \\ Contributions: (I) Conception and design: All authors; (II) Administrative support: JZ Sun; (III) Provision of study materials or patients: All authors; (IV) \\ Collection and assembly of data: MH Zhou, Y Wu; (V) Data analysis and interpretation: All authors; (VI) Manuscript writing: All authors; (VII) Final \\ approval of manuscript: All authors. \\ "These authors contributed equally to this work. \\ Correspondence to: Jun-Zhong Sun. Department of Geriatric Oncology, Fourth Medical Center of the People's Liberation Army General Hospital, 51 \\ Fucheng Road, Beijing 100048, China. Email: sjunzh07@163.com.
}

\begin{abstract}
Background: Brain metastases significantly reduce the survival of cancer patients. However, detailed researches on the clinical manifestations and prognoses of patients with brain metastases are lacking. The aim of this study was to investigate the clinical features and prognostic factors of cancer patients with brain metastases.

Methods: A retrospective study was conducted on patients with brain metastases who were treated in our hospital between January 2014 and January 2019. Comparison of overall survival (OS) was performed by the Kaplan-Meier method. Multivariate Cox regression models was used to identify prognostic factors for OS.

Results: A total of 190 patients with complete data and Eastern Cooperative Oncology Group performance status (ECOG PS) 0-2 were enrolled. Patients with brain metastases from different primary sites had significantly different survival time $(\mathrm{P}=0.001)$. Patients who had a longer survival time included female patients (47.4\%) (34 vs. 19 months, $\mathrm{P}=0.002)$, those with age <65 years (63.7\%) (29 vs. 18 months, $\mathrm{P}=0.002)$, with ECOG 0 or 1 (44.2\%) (32 vs. 21 months, $\mathrm{P}=0.005)$, with $\leq 3$ brain lesions $(61.1 \%$ ) (29 vs. 20 months, $\mathrm{P}=0.041$ ), and with small molecular targeted therapy (48.4\%) (21 vs. 18 months, $\mathrm{P}=0.006)$. Furthermore, multivariate analysis revealed that female, age $<65$ years, $\leq 3$ brain lesions, small molecular targeted therapy were independent favorable prognostic factors of OS.
\end{abstract}

Conclusions: Female, younger patients with $\leq 3$ brain metastases predicted a better survival. To improve the poor outcomes of these patients, it is necessary to find clinically significant genetic abnormalities and administer the small molecular targeted therapy early in the course of treatment.

Keywords: Brain metastasis; cancer; prognostic factor; small molecular targeted therapy.

Submitted Sep 23, 2019. Accepted for publication Dec 17, 2019.

doi: $10.21037 /$ tcr.2019.12.98

View this article at: http://dx.doi.org/10.21037/tcr.2019.12.98

\section{Introduction}

Brain metastases significantly reduce the survival of cancer patients. Many patients have neurological symptoms when brain metastases are identified $(1,2)$. Systemic chemotherapies for patients with brain metastases are limited because of the poor penetration of the bloodbrain barrier $(3,4)$. Many molecular targeted therapies show intracranial effect $(5,6)$, but most cancer patients are unsuitable for targeted therapy. Therefore, local therapies of brain metastases are important, including surgery, stereotactic radiosurgery (SRS) and whole brain radiotherapy (WBRT). SRS was reported to have the same local effect as surgery in select patients, and to have significantly less neurocognitive toxicity compared with WBRT $(7,8)$. The treatment of brain metastases 
should be highly tailored to individual patients decided by a multidisciplinary team. Lung and breast cancers are the most common primary tumors in patients with brain metastases $(9,10)$.

Because of the low incidence of brain metastases in cancer patients $(11,12)$, detailed researches on the clinical manifestation and prognoses of patients with brain metastases are currently lacking. The aim of this study was to investigate the clinical features and prognostic factors of cancer patients with brain metastases admitted to our hospital in the past 5 years.

\section{Methods}

\section{Patients and methods}

A retrospective study was conducted on cancer patients with brain metastases who were treated in our hospital between January 2014 and January 2019. All diagnoses of cancer patients were confirmed by histopathology. Those patients with ECOG $>2$ or hematological malignancies were excluded. A total of 190 cancer patients with brain metastases and complete clinical and follow-up data were included in our study. The collected data on patients included demographics, Eastern Cooperative Oncology Group performance status (ECOG PS), interval time from cancer diagnosis to brain metastases, primary tumor, symptom at the time of brain metastases, number of brain metastases, extracranial metastatic lesions (lung, liver or bone), systemic antitumor therapy, local therapy for brain metastases and survival time. Systemic antitumor therapies included cytotoxic chemotherapy, small molecular targeted therapy, hormone therapy and immunotherapy. Local therapies for brain metastases included surgery, SRS and WBRT. The study was approved by the ethics committee of our institute (2019KY024_KS001). Informed consent was not required because of the retrospective nature of the study.

\section{Statistics}

The clinical data were summarized as $\mathrm{n}(\%)$ for categorical variables and median with range for continuous variables. Overall survival (OS) was calculated by the Kaplan-Meier method with the SPSS 17.0 statistics software (SPSS Inc., Chicago, IL, USA). OS was defined as the time from the date of brain metastases to the date of death or the end of the study (July 2019). Comparison of survival was performed using the log-rank test. Multivariate Cox regression models were used to identify the prognostic factors for OS. A P value $<0.05$ was considered statistically significant.

\section{Results}

\section{Patient characteristics}

A total of 190 cancer patients with brain metastases were enrolled in this study. The clinical characteristics of these patients are shown in Table 1. One hundred patients (52.6\%) were male and $90(47.4 \%)$ were female. The median age of all patients was 60 years (range, 29-87 years), 121 (63.7\%) were age $<65$ years and $69(36.3 \%)$ were age $\geq 65$ years. There were 84 (44.2\%) patients with ECOG 0-1 and 106 (55.8\%) patients with ECOG 2. The median interval time from cancer diagnosis to brain metastases was 10.5 months (range, $0-102$ months), 80 patients $(42.1 \%$ ) had a metastasis interval $\leq 6$ months and $110(57.9 \%)$ had a metastasis interval $>6$ months. Brain metastases were primarily identified by MRI (178, 93.7\%), but also by CT or PET/ CT $(6,3.2 \%$, respectively).

In the 190 patients with brain metastases, 123 (64.7\%) patients were diagnosed with non-small cell lung cancer, $33(17.4 \%)$ patients with small cell lung cancer, 16 (8.4\%) patients with breast cancer, 4 patients with colorectal cancer, 3 patients with gastric cancer, 2 patients with liver, kidney, esophagus cancer, respectively, 1 patient with melanoma, ovarian, thymic, endometrial, apocrine cancer, respectively. At the diagnoses of brain metastases, 125 patients had no related symptom. In the symptomatic patients, headache (19, $10 \%)$ was the most common, followed by vertigo (13, $6.8 \%)$ and different degrees of hemiplegia (10, 5.3\%).

The number of brain metastases was varied in patients. A total of 116 patients $(61.1 \%$ ) had 3 or less than 3 brain lesions, and 74 patients (38.9\%) had more than 3 lesions. Extracranial lesion in lung, liver or bone in patients was analyzed. Seventy-four patients (38.9\%) had none of the above extracranial lesions. One extracranial lesion was found in 80 patients $(42.1 \%)$, and two or three lesions were found in 36 patients (18.9\%). Ninety-two (48.4\%) patients received small molecular targeted therapy, and the rest of the 98 patients $(51.6 \%)$ did not. Local therapy for brain metastases was given in 147 patients $(77.4 \%)$, not in the other 43 patients (22.6\%).

\section{Survival after brain metastases and prognostic factors of $O S$}

The median follow-up time was 18 months (range, 3-92 months). Patients with brain metastases from different primary sites 
Table 1 Clinical characteristics of cancer patients with brain metastases

\begin{tabular}{|c|c|}
\hline Characteristic & Number of patients (\%) \\
\hline Total & 190 \\
\hline \multicolumn{2}{|l|}{ Gender } \\
\hline Male & $100(52.6)$ \\
\hline Female & $90(47.4)$ \\
\hline \multicolumn{2}{|l|}{ Age (years) } \\
\hline Median, range & $60,29-87$ \\
\hline$<65$ & $121(63.7)$ \\
\hline$\geq 65$ & 69 (36.3) \\
\hline \multicolumn{2}{|l|}{ ECOG PS } \\
\hline 0,1 & $84(44.2)$ \\
\hline 2 & $106(55.8)$ \\
\hline \multicolumn{2}{|l|}{$\begin{array}{l}\text { Interval from cancer to brain } \\
\text { metastases (months) }\end{array}$} \\
\hline Median, range & $10.5,0-102$ \\
\hline$\leq 6$ months & $80(42.1)$ \\
\hline$>6$ months & $110(57.9)$ \\
\hline \multicolumn{2}{|l|}{ Brain metastases diagnosis by } \\
\hline MRI & $178(93.7)$ \\
\hline CT & $6(3.2)$ \\
\hline $\mathrm{PET} / \mathrm{CT}$ & $6(3.2)$ \\
\hline \multicolumn{2}{|l|}{ Primary site } \\
\hline Non-small cell lung cancer & $123(64.7)$ \\
\hline Small cell lung cancer & $33(17.4)$ \\
\hline Breast cancer & $16(8.4)$ \\
\hline Others & $18(9.5)$ \\
\hline Colorectal cancer & $4(2.1)$ \\
\hline Gastric cancer & $3(1.6)$ \\
\hline $\begin{array}{l}\text { Liver/kidney/esophagus cancer, } \\
\text { respectively }\end{array}$ & $2(1.1)$ \\
\hline $\begin{array}{l}\text { Melanoma ovarian/thymic/ } \\
\text { endometrial/apocrine cancer, } \\
\text { respectively }\end{array}$ & $1(0.5)$ \\
\hline
\end{tabular}

Table 1 (continued)

had significantly different survival time (non-small cell lung cancer with 28 months $v$ s. small cell lung cancer with 16 months $v s$. breast cancer with 53 months $v s$. others
Table 1 (continued)

\begin{tabular}{lc}
\hline Characteristic & Number of patients (\%) \\
\hline Symptom & $125(65.8)$ \\
No & $19(10.0)$ \\
Headache & $13(6.8)$ \\
Vertigo & $10(5.3)$ \\
Hemiplegia & $6(3.2)$ \\
Seizure & $5(2.6)$ \\
Weakness/ataxia, respectively & $4(2.1)$ \\
Altered speech & $3(1.6)$ \\
Blurred vision & \\
Number of BM & $116(61.1)$ \\
$\leq 3$ & $74(38.9)$ \\
$>3$ & \\
Extracranial lesions & \\
Lung/liver/bone, respectively & $98(48.4)$ \\
0/1/2/3 lesions, respectively & \\
Small molecular targeted therapy & \\
Yes & $74 / 14 / 58(4.2 / 7.4 / 30.5)$ \\
No & \\
BM, brain metastases. & \\
Yes & \\
No & \\
\hline
\end{tabular}

16 months, $\mathrm{P}=0.001)$. Patients who had a longer survival time included female patients (34 vs. 19 months, $\mathrm{P}=0.002$, Figure 1), those with age $<65$ years (29 vs. 18 months, $\mathrm{P}=0.002$, Figure 2), with ECOG 0 or 1 (32 vs. 21 months, $\mathrm{P}=0.005$ ), with $\leq 3$ brain lesions ( 29 vs. 20 months, $\mathrm{P}=0.041$, Figure 3), and with small molecular targeted therapy (21 vs. 18 months, $\mathrm{P}=0.006$, Figure 4). Furthermore, multivariate analysis revealed that female, age $<65$ years, $\leq 3$ brain lesions, small molecular targeted therapy were independent favorable prognostic factors of OS (Table 2).

\section{Discussion}

Cancer patients with brain metastases pose a clinical challenge and have a dismal prognosis $(13,14)$. Information 


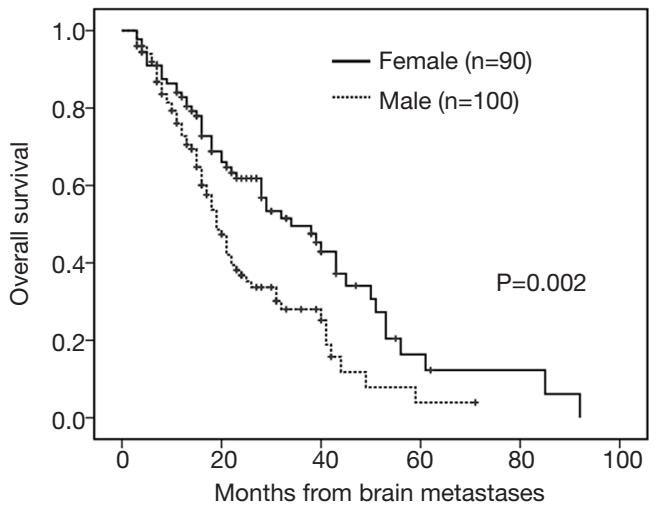

Figure 1 OS of patients: female $v s$. male. OS, overall survival.

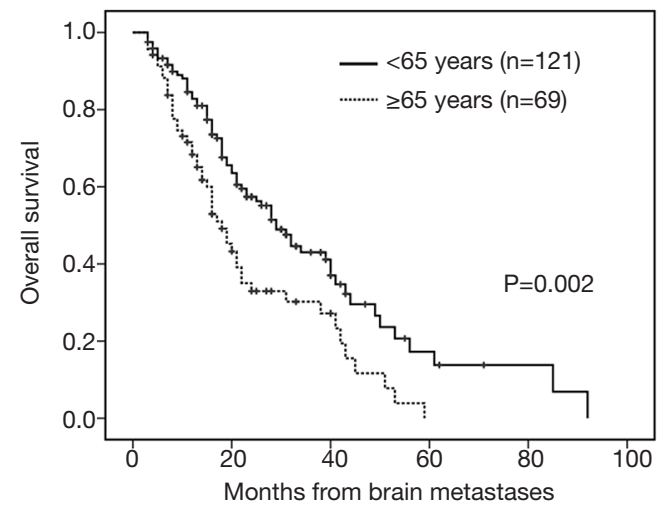

Figure 2 OS of patients: $<65$ vs. $\geq 65$ years. OS, overall survival.

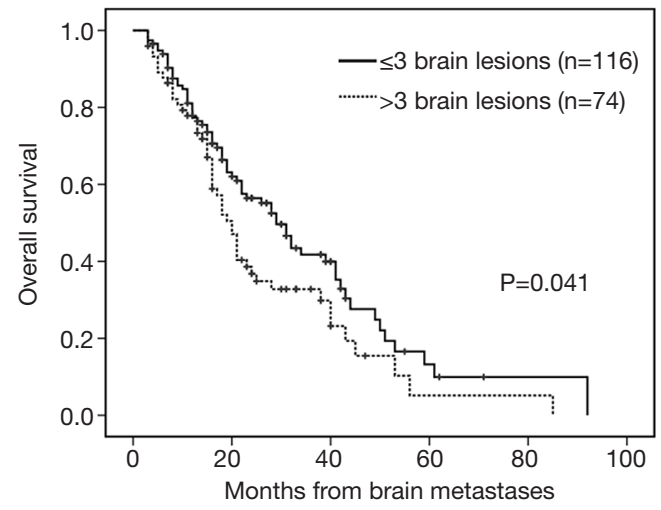

Figure 3 OS of patients: $\leq 3$ brain metastases $v s$. $>3$ brain metastases. OS, overall survival.

about clinical characteristics and prognostic factors is crucial to the diagnosis, therapy and prognosis of patients with brain metastases (1). In the current study, the clinical features and prognostic factors of 190 patients with brain

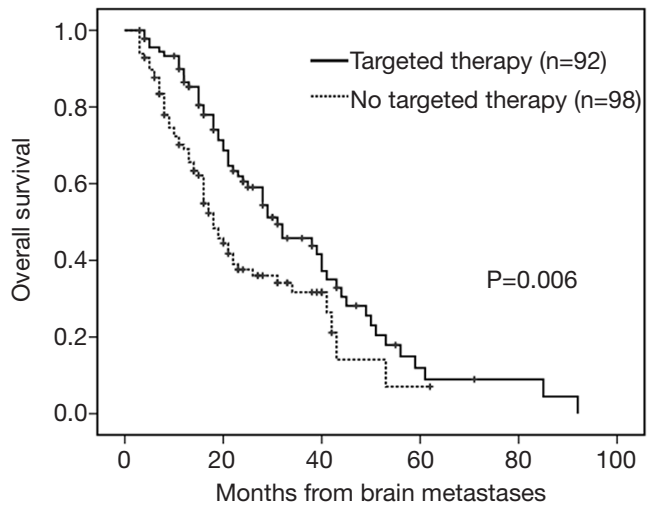

Figure 4 OS of patients: molecular targeted therapy $v s$. no molecular targeted therapy. OS, overall survival.

metastases were evaluated.

In this cohort, both gender and age were independent prognostic factors of OS. Female patients had a longer survival time, which could be explained by better prognosis of breast cancer patients. In addition, 60 percent of female patients (54 of 90 patients) received small molecular targeted therapy, while only 38 percent of male patients (38 of 100 patients) did. Rastogi et al. reported that survival was significantly improved in female patients (15). Young patients had a favorable prognosis, which was in line with other studies $(16,17)$.

Patients with good EOCG performance status have been reported to have better outcomes $(16,18)$. Similarly, in our study, patients with good performance status had a longer survival. However, no significant difference was found after multivariate analysis. This is perhaps because all patients included in our study were ECOG PS $\leq 2$, and there were no major differences in the intensity of treatment for these patients. Cacho-Diaz et al. reported that some symptoms were associated with poor outcomes in patients with brain metastases (1). In our study, there was no survival difference between patients with or without symptom associated with brain metastases at the diagnoses. Most of the patients in our study were found to have brain metastases at the regular screening in the absence of symptom, in contrast with the work of Cacho-Diaz et al., which found that the majority of patients had over one symptom at the time of diagnosis.

The prognoses in patients with brain metastases were significantly different depending on the type of primary cancer $(5,19)$. In our study, the best survival was observed in patients with breast cancer, followed by non-small cell lung cancer. Both of the tumors had more therapeutic 
Table 2 Univariate analysis and multivariate analysis of the prognostic factors of OS in cancer patients with BM

\begin{tabular}{|c|c|c|c|c|c|}
\hline Factors & \multicolumn{2}{|c|}{ Univariate analysis } & \multicolumn{3}{|c|}{ Multivariate analysis } \\
\hline Male & 19 & & & & \\
\hline Female & 34 & & & & \\
\hline$<65$ & 29 & & & & \\
\hline$\geq 65$ & 18 & & & & \\
\hline \multicolumn{6}{|l|}{ ECOG } \\
\hline $0-1$ & 32 & 0.005 & 1.460 & $0.979-2.176$ & 0.063 \\
\hline Non-small cell lung cancer & 28 & & & & \\
\hline Small cell lung cancer & 16 & & & & \\
\hline Breast cancer & 53 & & & & \\
\hline Others & 16 & & & & \\
\hline Interval from cancer to BM & & 0.220 & - & - & - \\
\hline$\leq 6$ months & 28 & & & & \\
\hline$>6$ months & 21 & & & & \\
\hline Symptom & & 0.636 & - & - & - \\
\hline$>3$ & 20 & & & & \\
\hline Extracranial lesions & & 0.089 & - & - & - \\
\hline 0 & 22 & & & & \\
\hline 1 & 29 & & & & \\
\hline $2-3$ & 18 & & & & \\
\hline Small molecular targeted therapy & & 0.006 & 1.604 & $1.091-2.359$ & 0.016 \\
\hline Yes & 31 & & & & \\
\hline No & 18 & & & & \\
\hline Local therapy for BM & & 0.654 & - & - & - \\
\hline Yes & 23 & & & & \\
\hline No & 24 & & & & \\
\hline
\end{tabular}

OS, overall survival; BM, brain metastases. 
modality options and were more sensitive to treatment. The interval time from cancer diagnosis to brain metastases was varied from 0 to 102 months. No survival difference was observed between the patients with less or more than a 6-month interval. This suggested that the diagnosis of brain metastases indicated a very poor prognoses irrespective of the interval time.

Patients with brain oligometastasis are believed to have a better survival than those with multiple brain metastases $(1,15)$. In our study, patients with $\leq 3$ brain metastatic lesions also had a favorable survival, which was an independent prognostic factor in the multivariate analysis. With regard to extracranial lesion of lung, liver or bone, there was no significant difference in survival correlated with various numbers of extracranial lesions. The probable cause here was that brain metastasis was a markedly poor prognostic factor regardless of extracranial lesion. However, a report from Ekici showed that patients with extracranial lesion had a shorter survival than those with only brain metastasis (18). More studies are needed to elucidate the clinical significances of extracranial lesions.

Effective local treatments for brain metastases include surgery, SRS and WBRT (20,21). In our study, patients who received local therapy for brain metastases received no survival benefit. Local therapies may be useful of yielding a local control and relieving the symptom of patients with brain metastases, but in our cohort, they did not improve survival time. Small molecular targeted drugs can penetrate the blood-brain barrier and have a better therapeutic effect than systemic chemotherapy $(5,22)$. This may explain that patients given with small molecular targeted therapy had a longer survival and the targeted therapy was a positive independent prognostic factor in our study. This finding was in good agreement with the results of a study by Füreder et al. (23).

\section{Conclusions}

In conclusion, the favorable independent prognostic factors for patients with brain metastases were female, younger age, fewer brain metastases and small molecular targeted therapy. Female, younger patients with less than or equal to 3 brain metastases predicted a better survival. To improve the poor outcomes of patients with brain metastases, it is necessary to find clinically significant genetic abnormalities whenever possible and administer the small molecular targeted therapy early in the course of treatment.

\section{Acknowledgments}

Funding: None.

\section{Footnote}

Conflicts of Interest: All authors have completed the ICMJE uniform disclosure form (available at http://dx.doi. org/10.21037/tcr.2019.12.98). The authors have no conflicts of interest to declare.

Ethical Statement: The authors are accountable for all aspects of the work in ensuring that questions related to the accuracy or integrity of any part of the work are appropriately investigated and resolved. The study was conducted in accordance with the Declaration of Helsinki (as revised in 2013). The study was approved by the ethics committee of our institute. Informed consent was not required because of the retrospective nature of the study. The patient's personal data have been secured.

Open Access Statement: This is an Open Access article distributed in accordance with the Creative Commons Attribution-NonCommercial-NoDerivs 4.0 International License (CC BY-NC-ND 4.0), which permits the noncommercial replication and distribution of the article with the strict proviso that no changes or edits are made and the original work is properly cited (including links to both the formal publication through the relevant DOI and the license). See: https://creativecommons.org/licenses/by-nc-nd/4.0/.

\section{References}

1. Cacho-Diaz B, Lorenzana-Mendoza NA, ChavezHernandez JD, et al. Clinical manifestations and location of brain metastases as prognostic markers. Curr Probl Cancer 2019;43:312-23.

2. Benna M, Mejri N, Mabrouk M, et al. Brain metastases epidemiology in a Tunisian population: trends and outcome. CNS Oncol 2018;7:35-9.

3. Nam JY, O'Brien BJ. Current chemotherapeutic regimens for brain metastases treatment. Clin Exp Metastasis 2017;34:391-9.

4. Muldoon LL, Soussain C, Jahnke K, et al. Chemotherapy delivery issues in central nervous system malignancy: a reality check. J Clin Oncol 2007;25:2295-305.

5. Di Lorenzo R, Ahluwalia MS. Targeted therapy of brain 
metastases: latest evidence and clinical implications. Ther Adv Med Oncol 2017;9:781-96.

6. Lin NU. Targeted therapies in brain metastases. Curr Treat Options Neurol 2014;16:276.

7. Linskey ME, Andrews DW, Asher AL, et al. The role of stereotactic radiosurgery in the management of patients with newly diagnosed brain metastases: a systematic review and evidence-based clinical practice guideline. J Neurooncol 2010;96:45-68.

8. Muacevic A, Wowra B, Siefert A, et al. Microsurgery plus whole brain irradiation versus Gamma Knife surgery alone for treatment of single metastases to the brain: a randomized controlled multicentre phase III trial. J Neurooncol 2008;87:299-307.

9. Berghoff AS, Schur S, Fureder LM, et al. Descriptive statistical analysis of a real life cohort of 2419 patients with brain metastases of solid cancers. ESMO Open 2016; 1:e000024.

10. Nayak L, Lee EQ, Wen PY. Epidemiology of brain metastases. Curr Oncol Rep 2012;14:48-54.

11. Ostrom QT, Wright CH, Barnholtz-Sloan JS. Brain metastases: epidemiology. Handb Clin Neurol 2018;149:27-42.

12. Gavrilovic IT, Posner JB. Brain metastases: epidemiology and pathophysiology. J Neurooncol 2005;75:5-14.

13. Cagney DN, Martin AM, Catalano PJ, et al. Incidence and prognosis of patients with brain metastases at diagnosis of systemic malignancy: a population-based study. Neuro Oncol 2017;19:1511-21.

14. Rotta JM, Rodrigues DB, Diniz JM, et al. Analysis of survival in patients with brain metastases treated surgically: Impact of age, gender, oncologic status, chemotherapy, radiotherapy, number and localization of lesions, and primary cancer site. Rev Assoc Med Bras (1992)

Cite this article as: Zhou MH, Wu Y, Sun JZ. Clinical features and prognostic factors in 190 cancer patients with brain metastases. Transl Cancer Res 2020;9(2):1160-1166. doi: $10.21037 /$ tcr.2019.12.98
2018;64:717-22.

15. Rastogi K, Bhaskar S, Gupta S, et al. Palliation of Brain Metastases: Analysis of Prognostic Factors Affecting Overall Survival. Indian J Palliat Care 2018;24:308-12.

16. Pojskic M, Bopp MHA, Schymalla M, et al. Retrospective study of 229 surgically treated patients with brain metastases: Prognostic factors, outcome and comparison of recursive partitioning analysis and diagnosis-specific graded prognostic assessment. Surg Neurol Int 2017;8:259.

17. Jeene PM, de Vries KC, van Nes JGH, et al. Survival after whole brain radiotherapy for brain metastases from lung cancer and breast cancer is poor in 6325 Dutch patients treated between 2000 and 2014. Acta Oncol 2018;57:637-43.

18. Ekici K, Temelli O, Dikilitas M, et al. Survival and prognostic factors in patients with brain metastasis: Single center experience. J BUON 2016;21:958-63.

19. Crisan A, Badulescu F, Popescu M, et al. Therapeutical Attitude and Analysis of Results in Brain Metastases. Curr Health Sci J 2016;42:372-84.

20. Carapella CM, Oppido PA. Present Role of Surgery for Brain Metastases. World Neurosurg 2018;120:423-5.

21. Lippitz B, Lindquist C, Paddick I, et al. Stereotactic radiosurgery in the treatment of brain metastases: the current evidence. Cancer Treat Rev 2014;40:48-59.

22. Wrona A, Dziadziuszko R, Jassem J. Management of brain metastases in non-small cell lung cancer in the era of tyrosine kinase inhibitors. Cancer Treat Rev 2018;71:59-67.

23. Füreder LM, Widhalm G, Gatterbauer B, et al. Brain metastases as first manifestation of advanced cancer: exploratory analysis of 459 patients at a tertiary care center. Clin Exp Metastasis 2018;35:727-38. 